\title{
Effects of anodizing parameters and heat treatment on nanotopographical features, bioactivity, and cell culture response of additively manufactured porous titanium
}

S. Amin Yavari ${ }^{1 *}$, Y.C. Chai ${ }^{2,3,4}$, A.J. Böttger ${ }^{1}$, R. Wauthle ${ }^{5,6}$, J. Schrooten ${ }^{7}$, H. Weinans $^{1,8}$, A.A. Zadpoor ${ }^{1}$

${ }^{I}$ Faculty of Mechanical, Maritime, and Materials Engineering, Delft University of Technology (TU Delft), Mekelweg 2, 2628 CD, Delft, The Netherlands

${ }^{2}$ Prometheus, Division of Skeletal Tissue Engineering, Bus 813, O\&N1, Herestraat 49, KU Leuven, 3000 Leuven, Belgium.

${ }^{3}$ Tissue Engineering Laboratory, Skeletal Biology and Engineering Research Center, Bus 813, O\&N1, Herestraat 49, KU Leuven, 3000 Leuven, Belgium.

${ }^{4}$ Department of Biomedical Engineering, Faculty of Engineering, University of Malaya, 50603 Kuala Lumpur, Malaysia.

${ }^{5}$ KU Leuven, Department of Mechanical Engineering, Section Production Engineering, Machine Design and Automation (PMA), Celestijnenlaan 300B, 3001 Leuven, Belgium

${ }^{6} 3$ D Systems - LayerWise NV, Grauwmeer 14, 3001 Leuven

${ }^{7}$ Department of Metallurgy and Materials Engineering, KU Leuven, Kasteelpark Arenberg 44 PB2450, B-3001 Heverlee, Belgium

${ }^{8}$ Department of Orthopedics \& department of Rheumatology, UMC Utrecht, Heidelberglaan 100, 3584 CX, Utrecht, The Netherlands

* Corresponding author, email: s.aminyavari@tudelft.nl, tel: +31-15-2784172, fax: +31-15-2784717. 


\section{Abstract}

Anodizing could be used for bio-functionalization of the surfaces of titanium alloys. In this study, we use anodizing for creating nanotubes on the surface of porous titanium alloy bone substitutes manufactured using selective laser melting. Different sets of anodizing parameters (voltage: 10 or $20 \mathrm{~V}$ anodizing time: $30 \mathrm{~min}$ to $3 \mathrm{~h}$ ) are used for anodizing porous titanium structures that were later heat treated at $500^{\circ} \mathrm{C}$. The nanotopographical features are examined using electron microscopy while the bioactivity of anodized surfaces is measured using immersion tests in the simulated body fluid (SBF). Moreover, the effects of anodizing and heat treatment on the performance of one representative anodized porous titanium structures are evaluated using in vitro cell culture assays using human periosteum-derived cells (hPDCs). It has been shown that while anodizing with different anodizing parameters results in very different nanotopographical features, i.e. nanotubes in the range of 20 to $55 \mathrm{~nm}$, anodized surfaces have limited apatite-forming ability regardless of the applied anodizing parameters. The results of in vitro cell culture show that both anodizing, and thus generation of regular nanotopographical feature, and heat treatment improve the cell culture response of porous titanium. In particular, cell proliferation measured using metabolic activity and DNA content was improved for anodized and heat treated as well as for anodized but not heat-treated specimens. Heat treatment additionally improved the cell attachment of porous titanium surfaces and upregulated expression of osteogenic markers. Anodized but not heat-treated specimens showed some limited signs of upregulated expression of osteogenic markers. In conclusion, while varying the anodizing parameters creates different nanotube structure, it does not improve apatite-forming ability of porous titanium. However, both anodizing and heat treatment at $500^{\circ} \mathrm{C}$ improve the cell culture response of porous titanium.

Keywords: Anodizing, nano-texturing, porous biomaterials, heat treatment, and bone regeneration. 


\section{INTRODUCTION}

Recent advances in additive manufacturing techniques such as selective laser melting [1-7] and electron beam melting [8-12] have enabled manufacturing of highly porous metallic bone substitutes. In such biomaterials, the porosities are very well defined and could be precisely controlled at the micro-scale. It is therefore possible to manufacture any specific design of the micro-porous structure. The design space includes the type of repeating unit cell and the dimensions of the unit cell. By choosing the right type of the unit cell and unit cell parameters, porous metallic biomaterials such as porous titanium with mechanical properties close to those of bone or even lower could be manufactured [13, 14]. Moreover, the highly porous structure provides ample space for bone ingrowth and for incorporation of drug delivery vehicles such as gels containing growth factors and other biologically stimulating agents [15]. The highly porous structure of these biomaterials also means huge surface area that could be used for bio-functionalization purposes. Surface treatments have been used for improving the bioactivity and bone regeneration performance of metallic biomaterials including titanium alloys [16-20]. We have recently shown that different types of surface treatments could significantly change the bone regeneration performance of porous titanium biomaterials manufactured using selective laser melting [21].

Anodizing [22-27] is one of the surface treatments that could be applied on titanium alloys. It is shown to significantly upregulate the expression of osteogenic markers in vitro [21]. Anodizing creates regular nanotopographical features, i.e. nanotubes, which are assumed to be responsible for such favorable behavior. More importantly, anodizing also improved the in vivo biomechanical stability of porous titanium implants as compared to other types of surface treatments [21]. Immersion experiments in simulated body fluid (SBF) [21], however, showed that anodized porous titanium does not form apatite crystals in vitro. Since high apatite forming ability is shown to be correlated with improved in vivo performance of biomaterials in most cases [28], it would be advantageous to improve the apatite forming ability of 
anodized porous titanium. In this study, we hypothesized that changing the anodizing parameters could modify the nanotopographical features and apatite-forming ability of anodized porous titanium. Moreover, we hypothesized that heat treatment could significantly change the in vitro cell response of anodized surface porous titanium.

To test both above-mentioned hypotheses, we performed a two-stage study. In the first stage, a wide range of anodizing parameters was used for surface treatment of a porous titanium structure manufactured using selective laser melting. The apatite forming ability of the specimens anodized with different anodizing parameters were then evaluated using SBF immersion tests. In the second stage, a representative set of anodizing parameters was used with and without heat treatment for surface treatment of the same type of porous titanium structures. The anodized specimens with and without heat treatment were then compared with each other using in vitro cell culture assays.

\section{MATERIALS AND METHODS}

\subsection{Materials and manufacturing}

The porous Ti6Al4V ELI samples used throughout this study were manufactured using the selective laser melting (SLM) technique (Layerwise NV, Belgium) as detailed in our previous study [29]. The specimens were disk shaped $(\varnothing 8 \mathrm{~mm} \times \mathrm{L} 3 \mathrm{~mm})$ with a nominal strut size of $120 \mu \mathrm{m}$ and a nominal pore size of $500 \mu \mathrm{m}$. The laser processing resulted in an energy input of $25.1 \mathrm{~J} / \mathrm{mm}^{3}$.

Analysis of the chemical composition of the manufactured parts was conducted at an ISO 9001 and ISO 17025 accredited lab. IGA (Interstitial Gas Analysis) was used to determine the concentration of C, N, O, H, whilst ICP-OES (Inductively Coupled Plasma Optical Emission Spectrometry) was used to determine concentration of $\mathrm{Al}, \mathrm{Ti}, \mathrm{V}, \mathrm{Fe}$ and $\mathrm{Y}$. Table 1 summarizes the results and compares them to the requirements of the standards ISO 5832-2 
and ASTM F136. The parts in this study were found to fulfill the requirements of the ISO 5832-2 and ASTM F136 standards in terms of the chemical composition (Table 1).

\subsection{Surface treatments and heat treatment}

To achieve $\mathrm{TiO}_{2}$ nanotubes on the surface of porous titanium, the porous structures were anodized [30]. Prior to anodizing, the oxide layer existing on surface of the porous structures was removed by immersing the specimens in an acidic mixture consisting of $2 \mathrm{~mL} 48 \% \mathrm{HF}, 3$ $\mathrm{mL} \mathrm{70 \%} \mathrm{HNO}_{3}$ (both Sigma-Aldrich), and $100 \mathrm{~mL}$ distilled water for $5 \mathrm{~min}$. Ti was used as the working electrode (anode) and platinum as the cathode. The electrolyte was a dilute $0.5 \mathrm{wt} \% \mathrm{HF}$ (Sigma -Aldrich) solution that was kept at room temperature throughout the anodizing process. To optimize the anodizing parameters, we choose two different anodizing voltages, namely 10 and $20 \mathrm{~V}$, while varying the anodizing time between $30 \mathrm{~min}$ and 3 hours. After anodizing, the specimens were rinsed with water and air-dried.

To apply the heat treatment, the anodized specimens were annealed at $500{ }^{\circ} \mathrm{C}\left(10{ }^{\circ} \mathrm{C} / \mathrm{min}\right)$ for 1 hour in an argon furnace (100 mm $\mathrm{Hg}$ ) and then gradually cooled down in the furnace to crystallize the amorphous $\mathrm{TiO} 2$ nanotubes. The structures of the oxide layers resulting from the different sets of parameters (either heat treated or non-heat treated) were examined using scanning electron microscopy (SEM). To study the effects of heat treatment on the cell culture response of the porous titanium, additional specimens were prepared using one representative set of anodizing parameters $(10 \mathrm{~V}, 1 \mathrm{~h})$ without applying the heat treatment.

\subsection{Surface characterization}

Surface morphologies of the titania nanotubes were studied with an FEI (DB strata 235, US) scanning electron microscope equipped with an energy dispersive X-ray analysis unit (EDAX, US). X-ray diffraction (XRD) analysis was conducted using a Bruker D5005 diffractometer equipped with Huber incident-beam monochromator and Braun PSD detector. Data collection was performed at room temperature using monochromatic copper radiation $K_{\alpha .1}(\lambda=0.154056$ 
$\mathrm{nm})$. Data was recorded between 20 and $60^{\circ} 2 \theta$ with a step size $0.0155^{\circ} 2 \theta$ and a counting time per step of $15 \mathrm{~s}$.

\subsection{Apatite forming ability test}

The apatite forming ability of surface-treated specimens was evaluated by immersing them in the simulated body fluid (SBF) [28] prepared according to ISO 13317:2012. The test procedures were accordance with the same standard.

\subsection{In vitro cell culture assay}

The in vitro cell culture response of anodized and heat treated $(\mathrm{AnH})$ specimens [21] was compared with that of anodized but not heat treated (An) specimens as well as with asmanufactured (AsM) specimens. Human periosteum-derived cells (hPDCs) pooled from six donors were expanded from liquid nitrogen in T-175 flask in growth medium (DMEMGlutaMax $^{\mathrm{TM}}-1+10 \% \mathrm{FBS}+1 \%$ antibiotic/antimycotic $+1 \%$ sodium pyruvate) and harvested upon confluent. Cells from different donors were first screened for cell proliferation in vitro as well as ectopic bone forming capacity in vivo in nude mouse. Then, the donor cells that were only with comparable population doubling time and ectopic bone forming capacity were made into the cell pool. In this way, the variation in biological behavior of different donors can be minimized. Additionally, all surface conditions received the same cell pool. Then, each scaffold was drop-seeded with 50,000 cells and incubated statically for $1 \mathrm{~h}$ to allow cell attachment before being transferred to a 3D rotator (GrantBio) for dynamic rotation seeding overnight [31]. Cell seeding efficiency was calculated by normalizing the DNA content of each sample after seeding to the DNA content of the cell suspension $(n=3)$ using Quant-iT ${ }^{\mathrm{TM}}$ dsDNA HS assay kit (Invitrogen). For cell proliferation assay, the cell-seeded scaffolds were transferred into 24-well plates and cultured for 21 days in growth medium. Cell proliferation was assessed by measuring the metabolic activity (PrestoBlue ${ }^{\circledR}$, Life technologies ${ }^{\mathrm{TM}}$ ) and total DNA content at defined time points. Cell viability on scaffolds was evaluated using the 
LIVE/DEAD ${ }^{\circledR}$ cell viability kit (Life technologies ${ }^{\mathrm{TM}}$ ) after 1, 7 and 21 days of culture. Cell culture morphology on the scaffolds was visualized by scanning electron microscopy coupled with energy dispersive spectrometry (SEM-EDAX, FEI XL30 FEG) at $10 \mathrm{kV}$.

The effects of heat treatment and anodizing on the osteogenic differentiation of hPDCs was evaluated by quantitative, real-time polymerase chain reaction (qPCR). Briefly, at 1, 7 and 21 days of culture, cell lysates were obtained by lysing cells in RLT buffer, followed by total RNA extraction (RNeasy extraction kit, Qiagen) and cDNA conversion (cDNA synthesis kit, Fermentas). Sybr Green qPCR primers that were designed to span an intron for specific RNA amplification were used for the PCR reactions using a Rotor-Gene sequence detector at $95{ }^{\circ} \mathrm{C}$ for 3 minutes, 40 cycles of $95{ }^{\circ} \mathrm{C}$ for 3 seconds, and $60{ }^{\circ} \mathrm{C}$ for 60 seconds $(n=3)$. Housekeeping $\beta$-Actin expression was used as an external control that allowed normalization of results. Relative expression level was calculated based on the $2^{-\mathrm{dCT}}$ method by normalizing the values to that of the housekeeping gene.

\section{RESUltS}

The different combinations of anodizing parameters resulted in very different sizes of nanotubes on the surface of porous titanium specimens (Figure 1). Depending on the anodizing parameters, the nanotube diameter was between $\approx 20$ to $\approx 55 \mathrm{~nm}$. When anodizing was continued for $3 \mathrm{~h}$, no regular nanotube structure was anymore found on the surface of the porous structure (Figure 1h). The regular nanotube structure was found in all other cases (Figure 1a-1g). The largest diameter of nano-tubes was found for $1 \mathrm{~h}$ time both for $10 \mathrm{~V}$ and $20 \mathrm{~V}$. The diameter of nano-tubes was smaller for the times less than 1 h (i.e. $30 \mathrm{~min}$ ) and the ones longer than $1 \mathrm{~h}$ (i.e. $2 \mathrm{~h}$ and $3 \mathrm{~h}$ ). A combination of large anodizing potential (i.e. $20 \mathrm{~V}$ ) and long anodizing time (i.e. $3 \mathrm{~h}$ ) did not result in any detectable nano-tubes (Figure $1 \mathrm{~h}$ ), while a combination of a short anodizing time (i.e. $30 \mathrm{~min}$ ) and a small anodizing potential (i.e. $10 \mathrm{~V}$ ) resulted in the coverage of the entire surface with small-diameter nanotubes 
(Figure 1a). The nanotubes were generally uniformly distributed all over the surface of specimens with similar nano-topographical patterns found throughout the surface of the same sample.

After 21 days immersion in SBF, no to very little apatite formation was observed on the surface of specimens regardless of the used anodizing parameters (Figure 2). X-ray diffraction analysis also confirmed that no apatite phases are present on the surface of the specimens immersed in the SBF for 21 days (Figure 3).

Live-dead staining showed a more uniform distribution of fluorescence readouts on the surface of AnH specimens as compared to both An and AsM specimens (Figure 4). In terms of cell attachment, AnH surfaces were covered with more cells as compared to An and AsM specimens (Figure 5). This was clear from the first days after the start of the cell culture experiments and continued until the end of the experiments (Figure 5). Quantitatively speaking, there was no significant difference between the cell seeding efficiency of the AsM, An, and AnH specimens (Figure 6a). However, cell proliferation measured using metabolic activity at 7 and 21 days was significantly higher for both An and AnH specimens as compared to AsM specimens (Figure 6b). The cell proliferation measured using DNA content was higher for An specimens at 7 days and for AnH specimens at 21 days, both compared to AsM specimens (Figure 6c).

As compared to AsM specimen, An specimens showed significantly higher levels of expression of Runx2 (21 days) and and Col1 (21 days) (Figure 7). However, there was one time point, i.e. 7 days, where An specimens showed lower levels of Runx2 expression as compared to AsM specimens (Figure 7). As for AnH specimens, they showed higher levels of expression of ALP (7 days), Col1 (21 days), and VEGF (1day) as compared to AsM specimens (Figure 7). There were no significant differences between An and AnH in terms of the level of expressions of any of the monitored osteogenic markers (Figure 7). 


\section{DisCUSSION}

The results of the study show that, indeed, different nanotopographical features, i.e. different sizes of nanotubes, could be created by varying the anodizing parameters (Figure 1). However, application of the different sets of anodizing parameters could not improve the apatite forming ability of anodized surfaces (Figure 2). It could be therefore concluded that anodized surfaces of the studied titanium alloy are not capable of forming apatite phases regardless of the anodizing parameters.

As for the effects of anodizing and heat treatment on the cell culture response of porous structures, the results of the study show clear signs that anodized and heat treated specimens perform better than as as-manufactured specimens (Figures 4-7). There were also signs that only anodized specimens also perform better than as-manufactured specimens (Figure 4-7). Comparing anodized specimens with anodized and heat treated specimens is more difficult. Qualitative results (Figures 4-5) showed that heat treatment clearly improves the cell attachment on the surface of porous structures. When comparing the expression of osteogenic markers between AnH and An specimens (Figure 7), one could clearly see that AnH specimens perform better than the control group, i.e. AsM specimens, for more markers are compared to AnH specimens (Figure 7). In particular, AnH specimens show significantly higher levels of ALP (day 7) and VEGF (day 1) expression as compared to AsM specimens while AnH specimens show no signs of significantly higher levels of expression as compared to AsM specimens for any of those markers. In case of Runx2, An specimens show inconsistent results: significantly lower level of Runx2 expression after 7 days and significantly higher level of Runx 2 expression after 21 days. One could therefore conclude that the expression of osteogenic markers is the best in the case of AnH specimens. In summary, both qualitative observations and quantitative results show that AnH specimens 
exhibit the best performance, meaning that the applied heat treatment has improved the cell culture response of anodized porous titanium structures.

Previous studies have shown that the bioactivity of anodized titanium alloys measured in terms of apatite forming ability could actually be quite low [21, 22, 32]. It has been also shown that heat treatment at high temperature could improve the apatite forming ability of titanium alloys [22, 32]. Previous studies have suggested that anodized titanium surfaces should be heat treated at temperature up to $800^{\circ} \mathrm{C}$ to obtain mostly rutile structure and, thus, drastically improved apatite forming ability [33]. Our previous study regarding the heat treatment of anodized porous titanium similar to the ones used in the current study show that, indeed, heat treatment at $400^{\circ} \mathrm{C}$ and above transforms the initially anatase oxide structure to rutile [30]. The percentage of rutile structure gradually increased as heat treatment was performed at higher temperatures up to $600^{\circ} \mathrm{C}$ and for a longer period of time [30]. However, the regular nanotopographical features created by anodizing were disrupted once the anodized porous structures were heat treated at $600^{\circ} \mathrm{C}$ [30]. This is an important point because several previous studies $[21,34-36]$ as well as the present study show that the presence of nanotopographical features is advantageous in terms of improved cell culture response of titanium alloys. Application of high temperature heat treatments for improving the apatite forming ability of anodized surfaces may therefore sacrifice the advantageous features offered by the regular nanotopographical features created by anodizing. Future studies should therefore focus on defining an optimum heat treatment protocol that could maximize apatiteforming ability of anodized titanium while not sacrificing the improved cell culture response offered by nanotopographical features. An alternative approach would be to, instead of heat treatment, use other techniques for improving the apatite forming ability of anodized porous titanium. For example, a technique called "alternative immersion method" [37] that preloads 
the surface of the biomaterial with synthetic hydroxyapatite could be used for improving the apatite forming ability of anodized porous titanium.

As previously discussed, the results of this study show that heat treatment improves the cell culture response of porous titanium. It is important to understand the mechanism through which heat treatment improves the cell culture response of porous titanium. Previous studies have shown that heat treatment could make the titanium surface more hydrophilic [38]. The improved hydrophilicity has been linked to the crystalline structure of the oxide layer [38]. The oxide layer was found to be amorphous on the samples that had not undergone heat treatment as opposed to the crystalline oxide layers present on the surface of heat-treated samples [38]. Since improved hydrophilicity is found to be associated with improved cell response and bone apposition [39], heat treatment may improve the cell culture response of anodized porous titanium by making it more hydrophilic. This is consistent with our qualitative observations in the current study regarding the better cell attachment and morphology in the case of AnH specimens as compared to An and AsM specimens (Figure 5). It could be therefore concluded that while heat treatment at lower temperature, e.g. $500^{\circ} \mathrm{C}$ as used in the current study, may not significantly improve the apatite forming ability of anodized porous titanium, it has the advantage of improving the cell culture response of porous titanium while not disrupting the regular nanotopographical features created by anodizing.

Anodizing with different voltages and anodizing times generated different nanotopographical features on the surface of porous titanium. Only one representative set anodizing parameters and the associated nanotopographical features were evaluated through cell culture experiments performed here. It is, however, important that future studies focus on the effects of such different nanotopographical features on the cell culture response of anodized porous titanium. Moreover, bone apposition is known to be dependent on mechanical forces [40-43]. 
On the other hand, morphological details of the porous structure at the micro-scale such as the type of the unit cell and unit cell dimensions are shown to determine the mechanical properties of the porous structure [3] and, thus, the distribution of mechanical forces. It is therefore important that, in addition to optimizing the nanotopographical features on the surface of porous titanium, the morphological design of the porous structure at the microscale is optimized possibly using patient-specific finite element models [44, 45].

In summary, the different sets of anodizing parameters were found to result in significantly different nanotopographies on the surface of anodized porous titanium. However, changing the anodizing parameters did not improve the apatite forming ability of anodized porous titanium. Both anodized and heat-treated and anodized but not heat-treated specimens exhibited improved cell culture response as compared to as-manufactured specimens. Moreover, application of heat treatment seems to improve the cell culture response of anodized specimens.

\section{REFERENCES}

[1] A. Fukuda, M. Takemoto, T. Saito, S. Fujibayashi, M. Neo, D.K. Pattanayak, T. Matsushita, K. Sasaki, N. Nishida, T. Kokubo, T. Nakamura, Acta Biomater, 7 (2011) 2327-2336.

[2] C.Y. Lin, T. Wirtz, F. LaMarca, S.J. Hollister, J Biomed Mater Res A, 83 (2007) 272-279.

[3] L. Mullen, R.C. Stamp, W.K. Brooks, E. Jones, C.J. Sutcliffe, J Biomed Mater Res B Appl Biomater, 89 (2009) 325-334.

[4] D.K. Pattanayak, A. Fukuda, T. Matsushita, M. Takemoto, S. Fujibayashi, K. Sasaki, N. Nishida, T. Nakamura, T. Kokubo, Acta Biomater, 7 (2011) 1398-1406.

[5] S. Van Bael, Y.C. Chai, S. Truscello, M. Moesen, G. Kerckhofs, H. Van Oosterwyck, J.P. Kruth, J. Schrooten, Acta Biomater, 8 (2012) 2824-2834.

[6] B. Vandenbroucke, J.-P. Kruth, Rapid Prototyping J, 13 (2007) 196-203.

[7] P.H. Warnke, T. Douglas, P. Wollny, E. Sherry, M. Steiner, S. Galonska, S.T. Becker, I.N. Springer, J. Wiltfang, S. Sivananthan, Tissue Eng Part C Methods, 15 (2008) 115-124.

[8] P. Heinl, C. Körner, R.F. Singer, Advanced Engineering Materials, 10 (2008) 882-888.

[9] P. Heinl, L. Müller, C. Körner, R.F. Singer, F.A. Müller, Acta Biomater, 4 (2008) 1536-1544. 
[10] X. Li, C. Wang, L. Wang, W. Zhang, Y. Li, Rare Metal Mat Eng, 39 (2010) 1697-1701.

[11] L. Murr, K. Amato, S. Li, Y. Tian, X. Cheng, S. Gaytan, E. Martinez, P. Shindo, F. Medina, R. Wicker, J Mech Behav Biomed Mater, 4 (2011) 1396-1411.

[12] J. Parthasarathy, B. Starly, S. Raman, A. Christensen, J Mech Behav Biomed Mater, 3 (2010) 249-259.

[13] G. Campoli, M.S. Borleffs, S. Amin Yavari, R. Wauthle, H. Weinans, A.A. Zadpoor, Mater Design, 49 (2013) 957-965.

[14] J. Van der Stok, O. Van der Jagt, S. Amin Yavari, M. De Haas, J. Waarsing, H. Jahr, E. Van Lieshout, P. Patka, J. Verhaar, A. Zadpoor, J Orthop Res, 31 (2013) 792-799.

[15] J. Van der Stok, H. Wang, S. Amin Yavari, M. Siebelt, M. Sandker, J.H. Waarsing, J.A.N. Verhaar, H. Jahr, A.A. Zadpoor, S.C.G. Leeuwenburgh, H. Weinans, Tissue Eng Part A, 19 (2013) 2605-2614.

[16] G. Giavaresi, M. Fini, A. Cigada, R. Chiesa, G. Rondelli, L. Rimondini, P. Torricelli, N.N. Aldini, R. Giardino, Biomaterials, 24 (2003) 1583-1594.

[17] H.-M. Kim, F. Miyaji, T. Kokubo, T. Nakamura, J Biomed Mater Res, 32 (1996) 409-417.

[18] G. Mendonça, D.B.S. Mendonça, F.J.L. Aragão, L.F. Cooper, Biomaterials, 29 (2008) 3822-3835.

[19] U. Turkan, M. Guden, Ceramics International, 36 (2010) 1805-1816.

[20] C. Zhao, X. Zhu, K. Liang, J. Ding, Z. Xiang, H. Fan, X. Zhang, J Biomed Mater Res B Appl Biomater, 95B (2010) 387-396.

[21] S. Amin Yavari, J. van der Stok, Y.C. Chai, R. Wauthle, Z. Tahmasebi Birgani, P. Habibovic, M. Mulier, J. Schrooten, H. Weinans, A.A. Zadpoor, Biomaterials, 35 (2014) 6172-6181.

[22] K. Das, S. Bose, A. Bandyopadhyay, Acta Biomater, 3 (2007) 573-585.

[23] D.S. Dunn, S. Raghavan, R.G. Volz, J Biomed Mater Res, 27 (1993) 895-900.

[24] E. George, C. Yao, T.J. Webster, Int J Nanomedicine, 3 (2008) 257-264.

[25] S. Minagar, C.C. Berndt, J. Wang, E. Ivanova, C. Wen, Acta Biomater, 8 (2012) 2875-2888.

[26] S. Minagar, J. Wang, C.C. Berndt, E.P. Ivanova, C. Wen, J Biomed Mater Res A, 101 (2013) 2726-2739.

[27] C. Yao, E.B. Slamovich, T.J. Webster, J Biomed Mater Res A, 85A (2008) 157-166.

[28] A.A. Zadpoor, Mater Sci Eng C Mater Biol Appl, 35 (2014) 134-143.

[29] S. Amin Yavari, R. Wauthle, J. van der Stok, A.C. Riemslag, M. Janssen, M. Mulier, J.P. Kruth, J. Schrooten, H. Weinans, A.A. Zadpoor, Mater Sci Eng C Mater Biol Appl, 33 (2013) 4849-4858.

[30] S. Amin Yavari, R. Wauthle, A.J. Böttger, J. Schrooten, H. Weinans, A.A. Zadpoor, Appl Surf Sci, 290 (2014) 287-294. 
[31] Y.C. Chai, S.J. Roberts, S. Van Bael, Y. Chen, F.P. Luyten, J. Schrooten, Tissue Eng Part C Methods, 18 (2011) 90-103.

[32] X.-X. Wang, W. Yan, S. Hayakawa, K. Tsuru, A. Osaka, Biomaterials, 24 (2003) 4631-4637.

[33] J. Forsgren, F. Svahn, T. Jarmar, H. Engqvist, Acta Biomater, 3 (2007) 980-984.

[34] K. Das, S. Bose, A. Bandyopadhyay, J Biomed Mater Res A, 90A (2009) 225-237.

[35] P.T. de Oliveira, S.F. Zalzal, M.M. Beloti, A.L. Rosa, A. Nanci, J Biomed Mater Res A, 80 (2007) 554-564.

[36] P. Tambasco de Oliveira, A. Nanci, Biomaterials, 25 (2004) 403-413.

[37] A. Kodama, S. Bauer, A. Komatsu, H. Asoh, S. Ono, P. Schmuki, Acta Biomater, 5 (2009) 2322-2330.

[38] T. Kern, Y. Yang, R. Glover, J.L. Ong, Implant dentistry, 14 (2005) 70-76.

[39] T. Sawase, R. Jimbo, K. Baba, Y. Shibata, T. Ikeda, M. Atsuta, Clinical oral implants research, 19 (2008) 491-496.

[40] S.L. Bass, L. Saxon, R. Daly, C.H. Turner, A.G. Robling, E. Seeman, S. Stuckey, Journal of bone and mineral research, 17 (2002) 2274-2280.

[41] G. Campoli, H. Weinans, F. van der Helm, A.A. Zadpoor, Journal of biomechanics, 46 (2013) 2434-2441.

[42] C.H. Turner, M. Forwood, J.Y. Rho, T. Yoshikawa, Journal of bone and mineral research, 9 (1994) 87-97.

[43] A.A. Zadpoor, J Mech Behav Biomed Mater, 27 (2013) 249-261.

[44] S. Poelert, E. Valstar, H. Weinans, A.A. Zadpoor, Proc Inst Mech Eng H, 227 (2013) 464-478.

[45] E. Schileo, F. Taddei, A. Malandrino, L. Cristofolini, M. Viceconti, Journal of biomechanics, 40 (2007) 2982-2989. 


\section{Table captions}

Table 1. Chemical composition of the manufactured parts and comparison with the relevant standards. 
Table 1

\begin{tabular}{lccccc}
\hline \multicolumn{5}{c}{ Percent mass fraction } \\
\hline ISO 5832-3 & $\begin{array}{c}\text { ASTM } \\
\text { F136 }\end{array}$ & $\begin{array}{c}\text { ASTM } \\
\text { F3001 }\end{array}$ & Tested part & Pass/fail \\
\hline Nitrogen, max & 0.05 & 0.05 & 0.05 & 0.022 & Pass \\
\hline Carbon, max & 0.08 & 0.08 & 0.08 & 0.011 & Pass \\
\hline Hydrogen, max & 0.015 & 0.012 & 0.012 & 0.0073 & Pass \\
\hline Iron, max & 0.3 & 0.25 & 0.25 & 0.18 & Pass \\
\hline Oxygen, max & 0.2 & 0.13 & 0.13 & 0.12 & Pass \\
\hline Yttrium, max & n.a. & n.a. & 0.005 & $<0.0001$ & Pass \\
\hline Aluminum & $5.5-6.75$ & $5.5-6.5$ & $5.5-6.5$ & 5.84 & Pass \\
\hline Vanadium & $3.5-4.5$ & $3.5-4.5$ & $3.5-4.5$ & 3.63 & Pass \\
\hline Titanium & balance & balance & balance & 90.35 & n.a. \\
\hline
\end{tabular}




\section{Figure captions}

Figure 1. SEM images of anodized porous titanium with the following parameters: $10 \mathrm{~V}, 30 \mathrm{~min}$ (a), $10 \mathrm{~V}, 1 \mathrm{~h}(\mathrm{~b}), 10 \mathrm{~V}, 2 \mathrm{~h}(\mathrm{c}), 10 \mathrm{~V}, 3 \mathrm{~h}(\mathrm{~d}), 20 \mathrm{~V}, 30 \mathrm{~min}(\mathrm{e}), 20 \mathrm{~V}, 1 \mathrm{~h}(\mathrm{f}), 20 \mathrm{~V}, 2 \mathrm{~h}(\mathrm{~g})$, and $20 \mathrm{~V}$, 3h (h).

Figure 2. SEM images of anodized porous titanium after 21 days of immersion in the SBF solution.

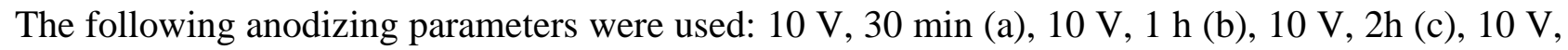
$3 \mathrm{~h}(\mathrm{~d}), 20 \mathrm{~V}, 30 \mathrm{~min}(\mathrm{e}), 20 \mathrm{~V}, 1 \mathrm{~h}(\mathrm{f}), 20 \mathrm{~V}, 2 \mathrm{~h}(\mathrm{~g})$, and $20 \mathrm{~V}$,

Figure 3. X-ray diffraction map for sample anodized specimens immersed in the SBF for 21 days. The following anodizing parameters were used: $10 \mathrm{~V}, 30 \mathrm{~min}$ (a) and $20 \mathrm{~V}, 3 \mathrm{~h}$ (b).

Figure 4. Live-dead staining of AsM (a, d) [21], An (b, e), and AnH [21] (c, f) specimens after 7 (up) and 21 (down) days of cell culture. Scale bar: $500 \mu \mathrm{m}$.

Figure 5. Cell attachment and morphology for AsM [21] (a, d, and g), An (b, e, and h), and AnH (c, f, and i) [21] specimens after 1 (up), 7 (middle), and 21 (down) days of cell culture.

Figure 6. Cell seeding efficiency (a) and cell proliferation measured using metabolic activity (b) and DNA content (c).

Figure 7. Expression of ALP (a), Runx2 (b), OCN (c), Osx (d), Col1 (e), and VEGF (f). The expression levels are measured using the relative mRNA expression after 1, 7, and 21 days of cell culture. 
Figure 1

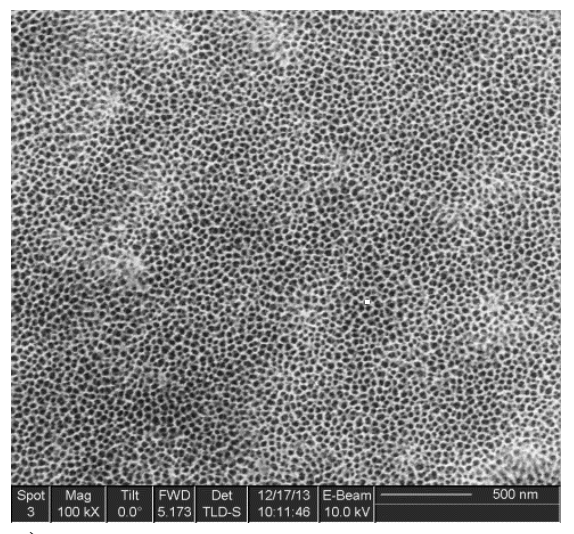

a)

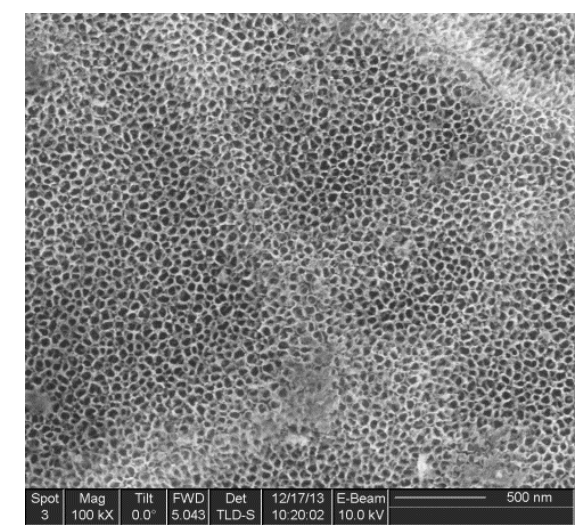

b)

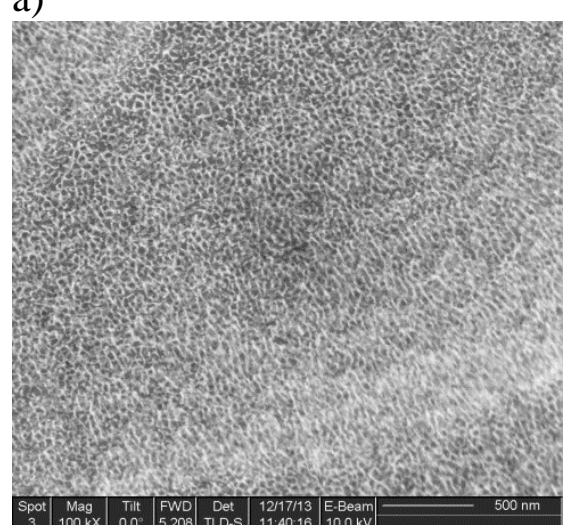

787 r

6.

Hon

3.1.

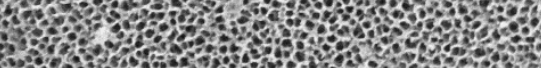

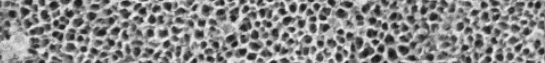

[Y,

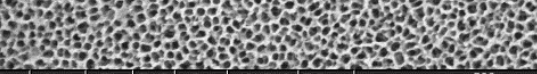

e)

f)

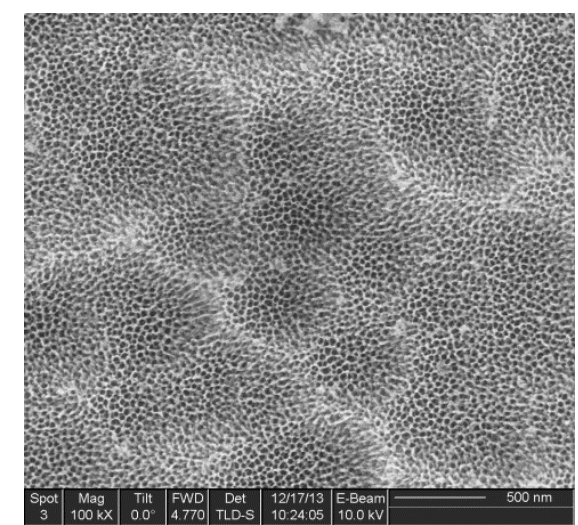

c)

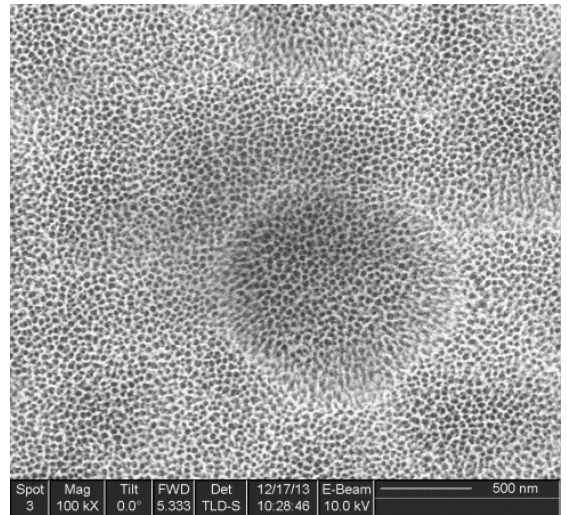

d)

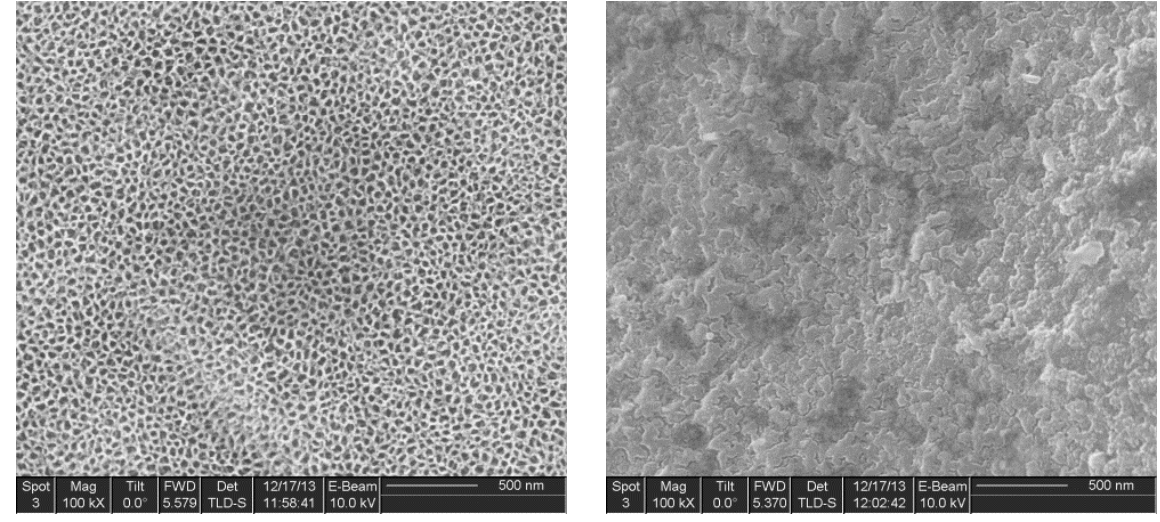

h) 
Figure 2

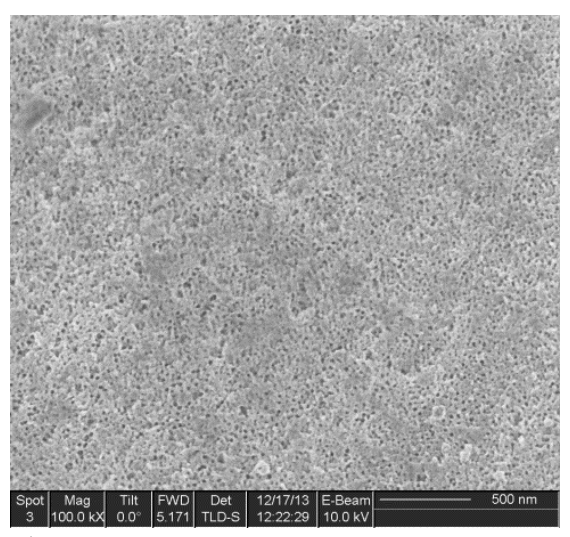

a) (b)

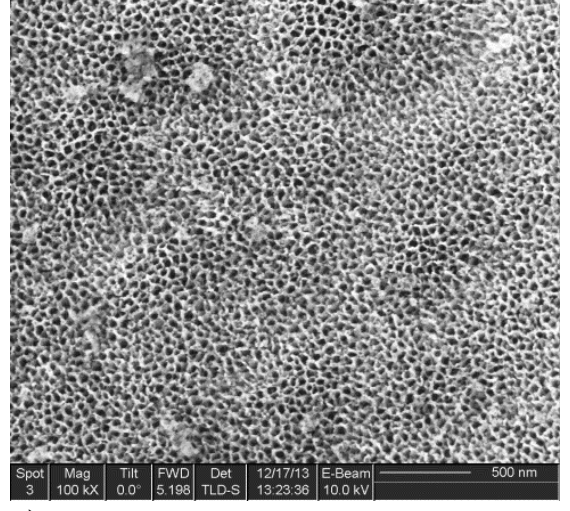

e)

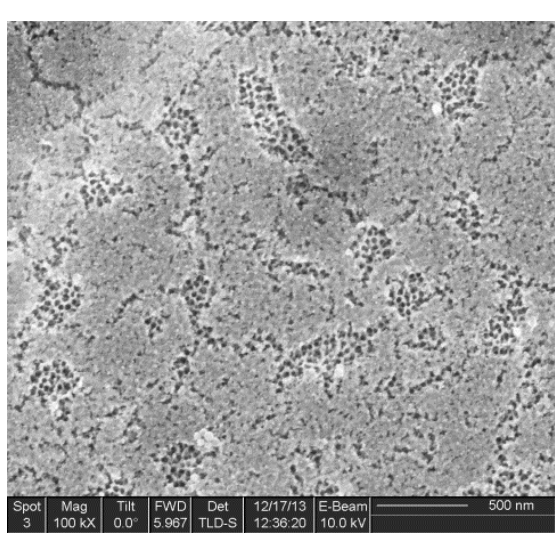

b)
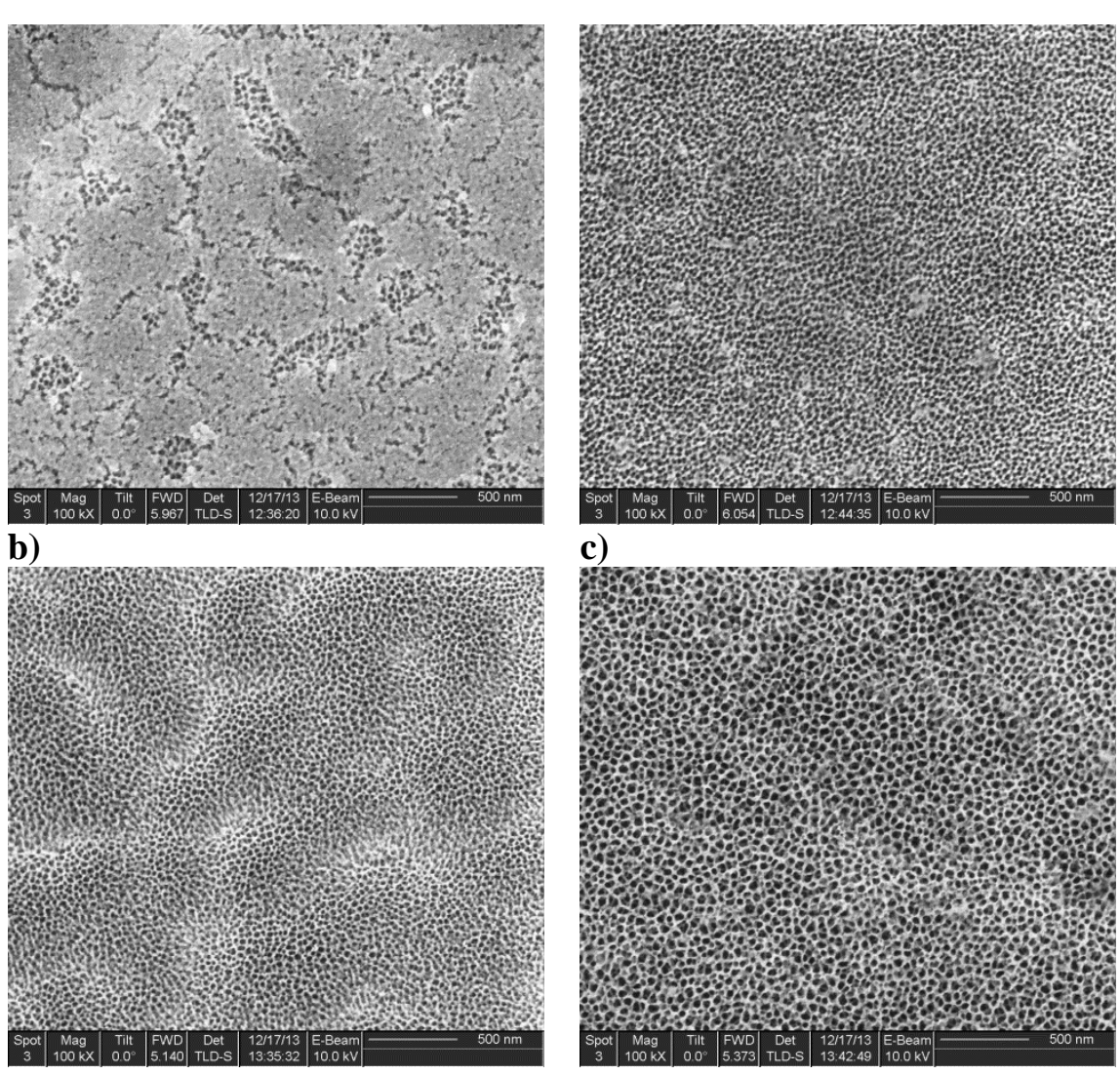

f) c)

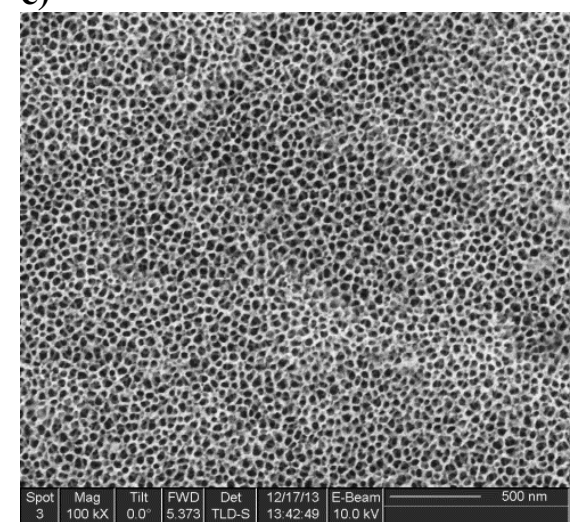

g)

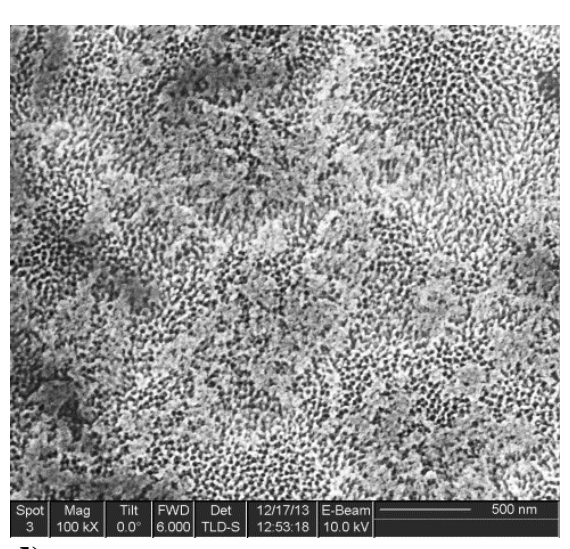

d)

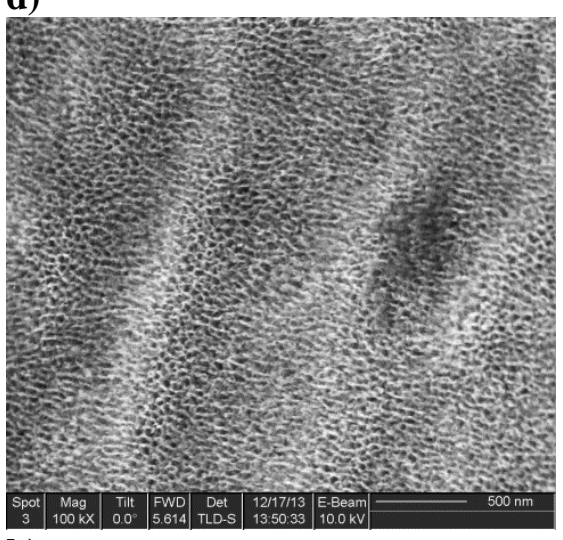
h) 
Figure 3

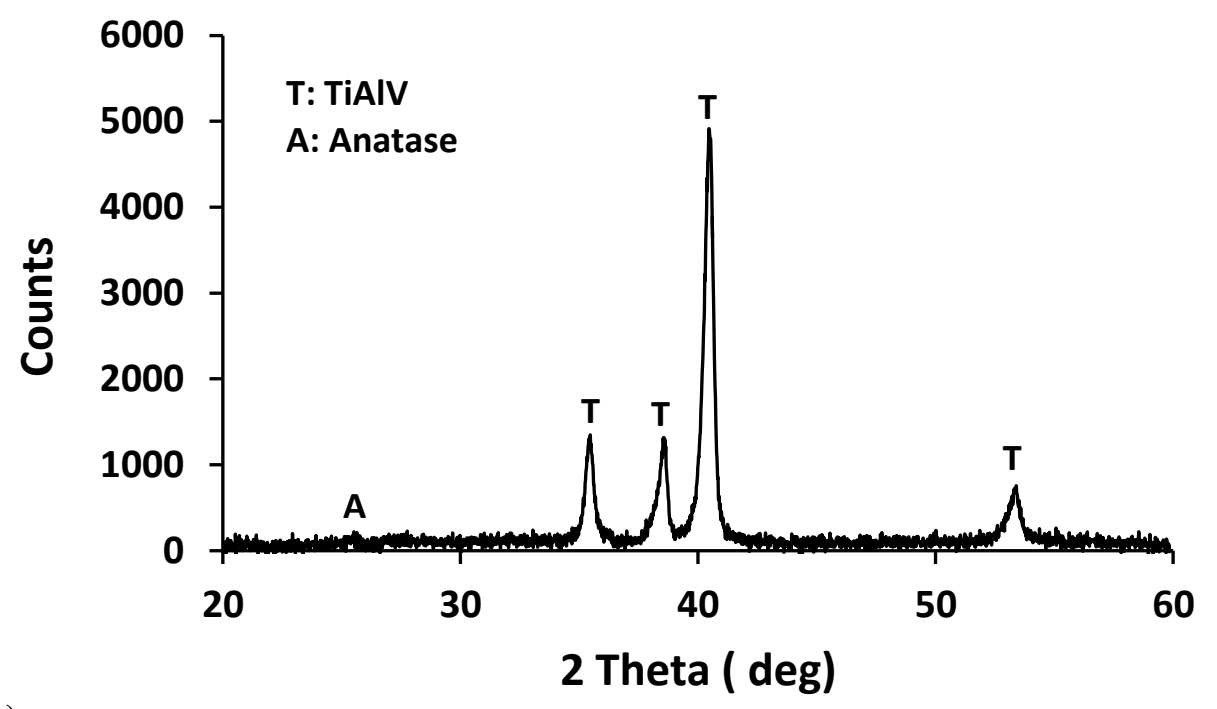

a)

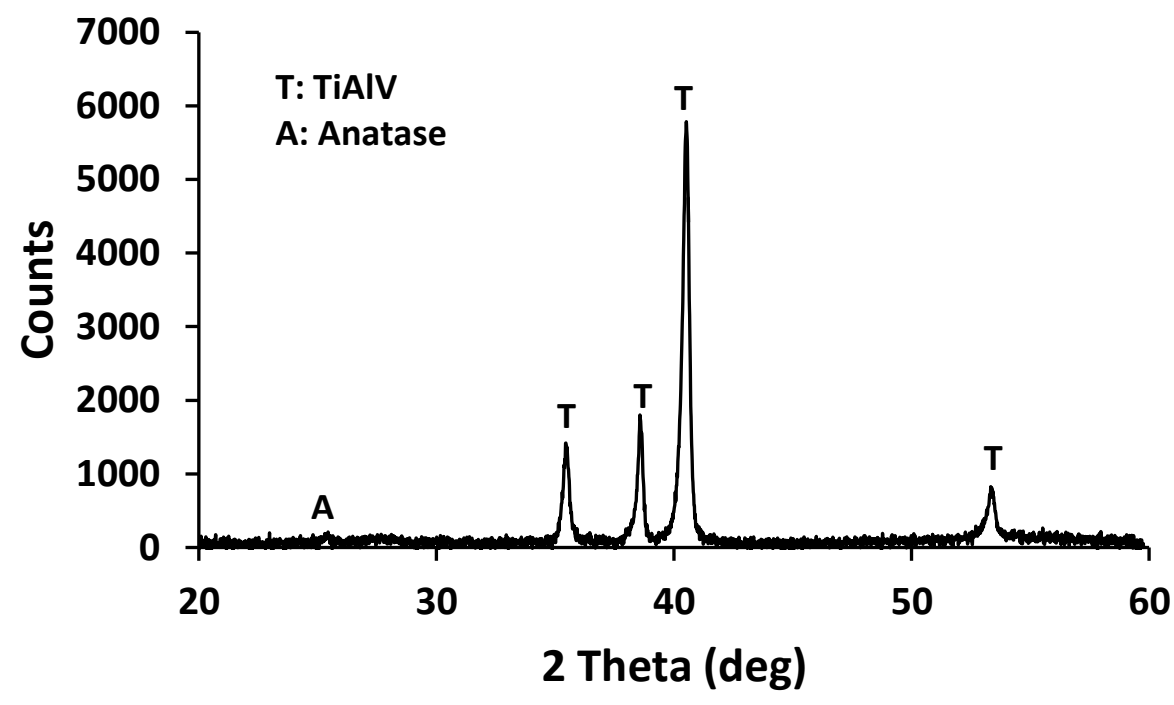

b) 
Figure 4
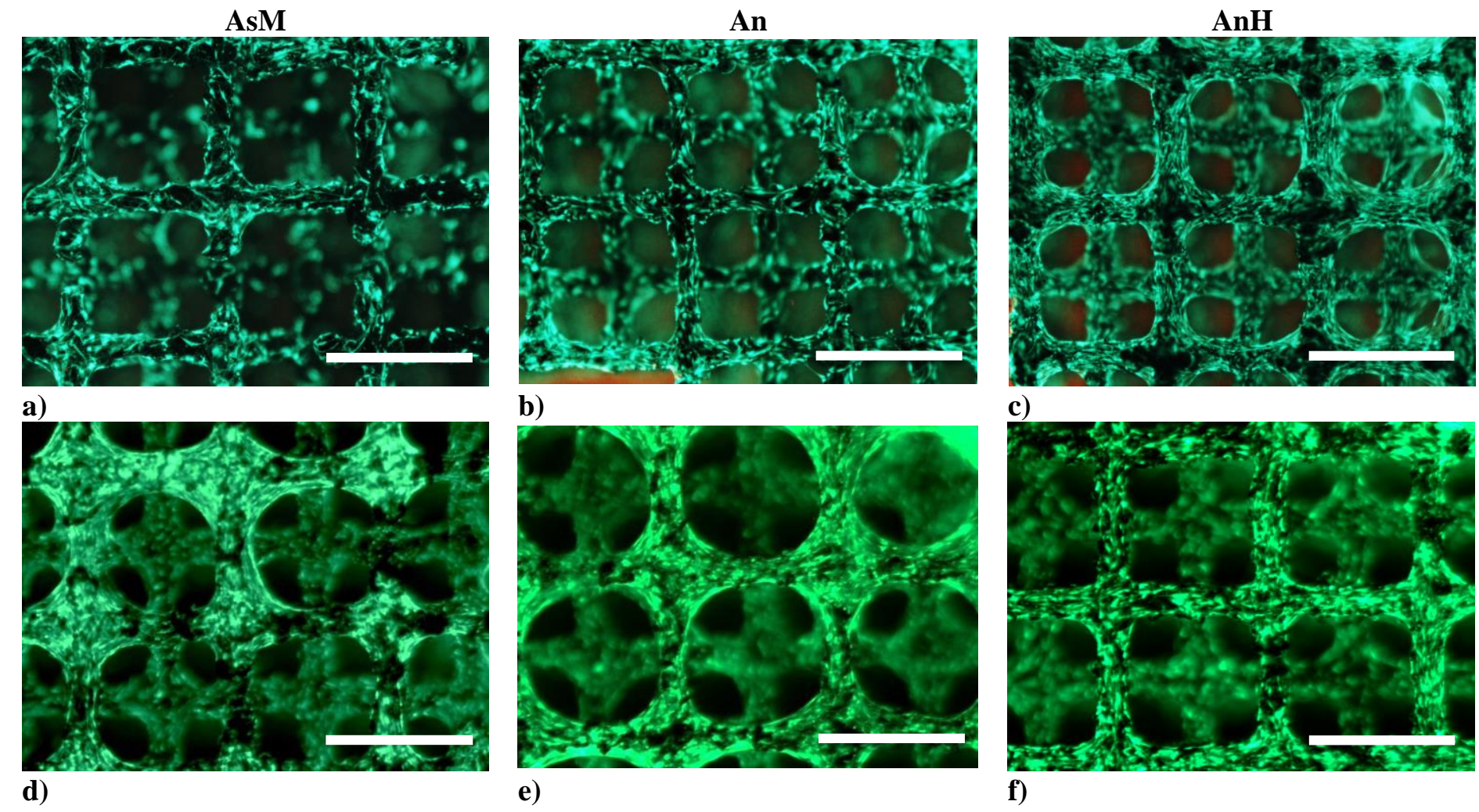
Figure 5
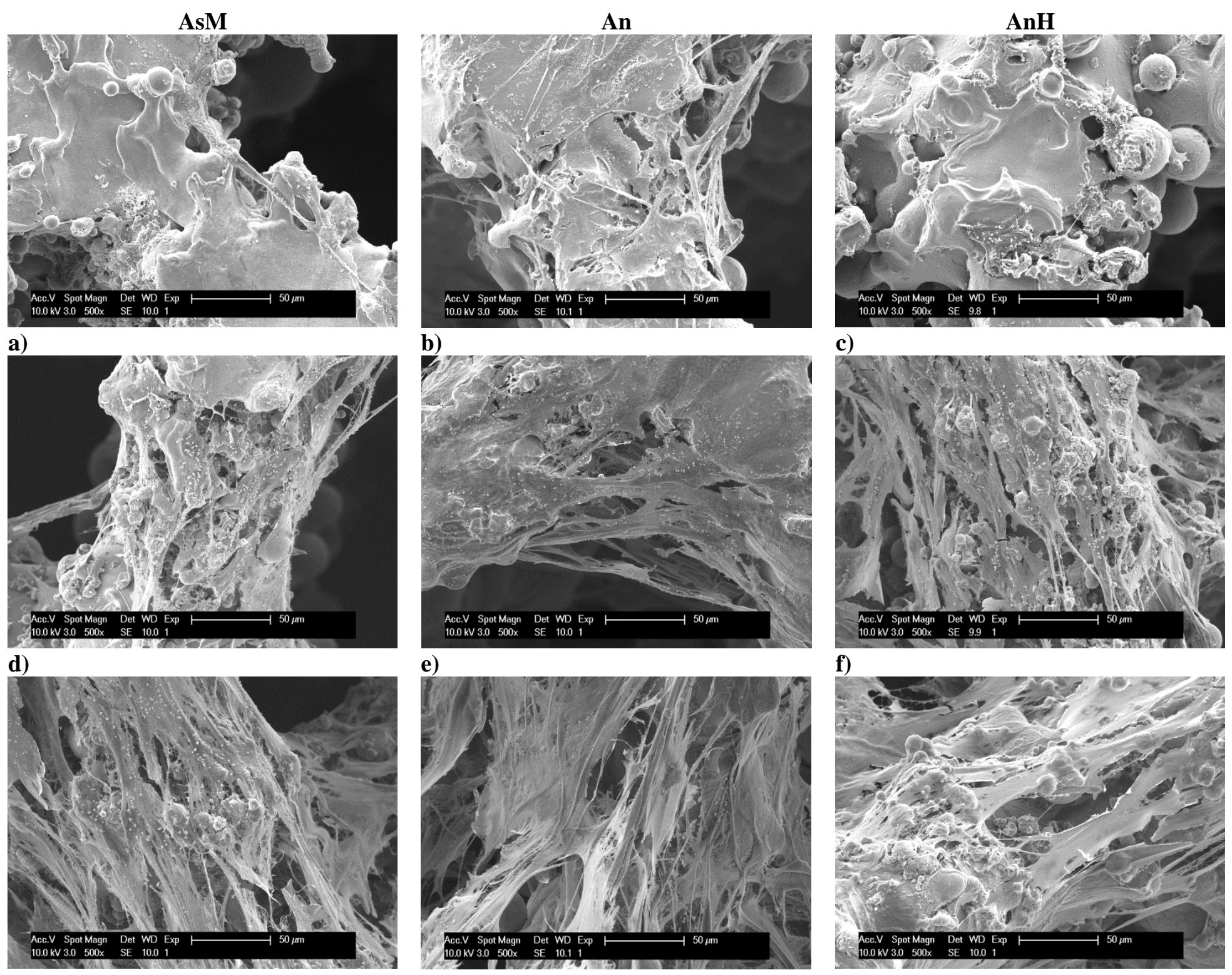

g)

h)

i) 
Figure 6

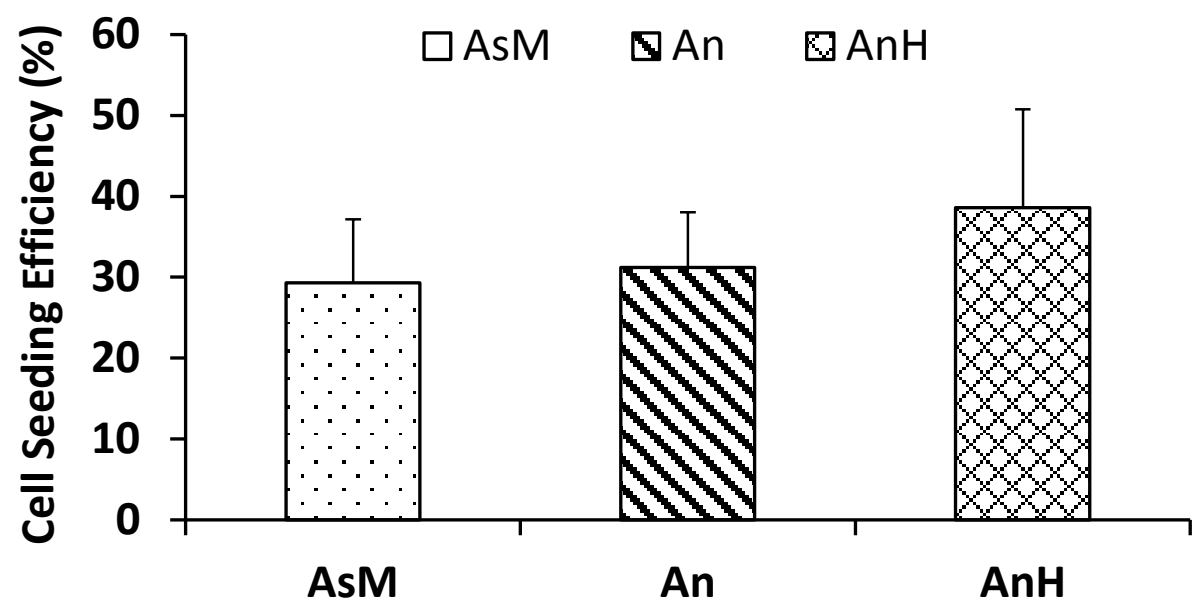

a)

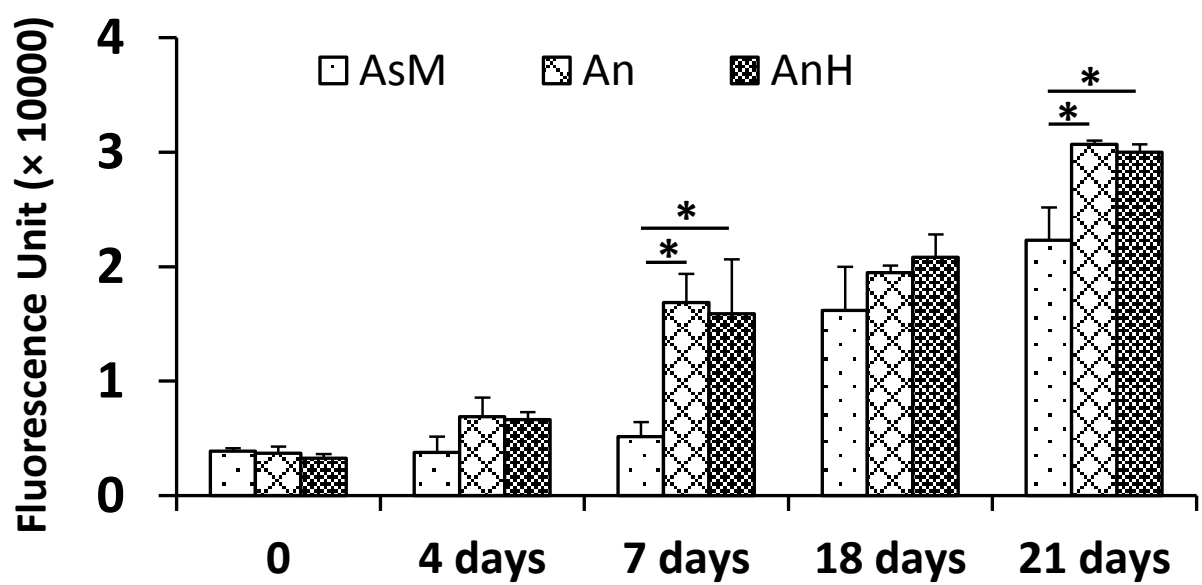

b)

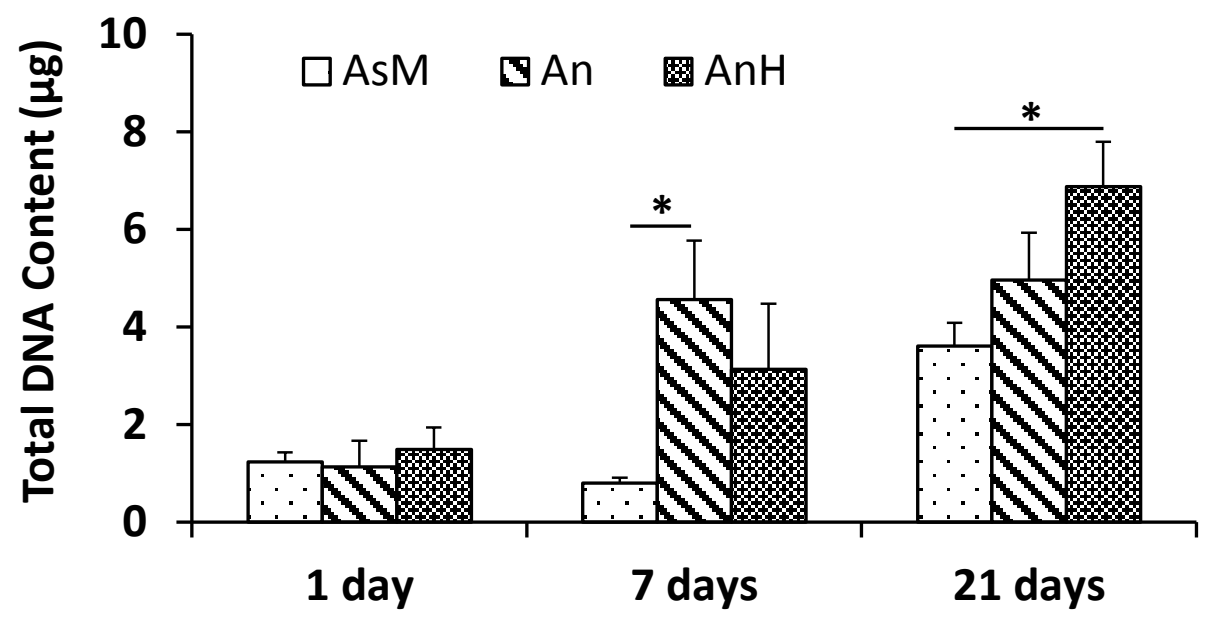

c) 


\section{Figure 7}
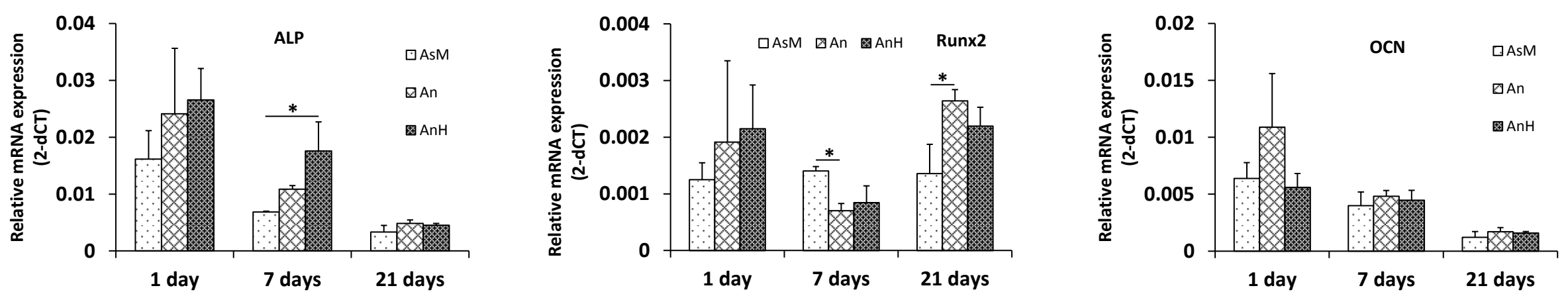

a)

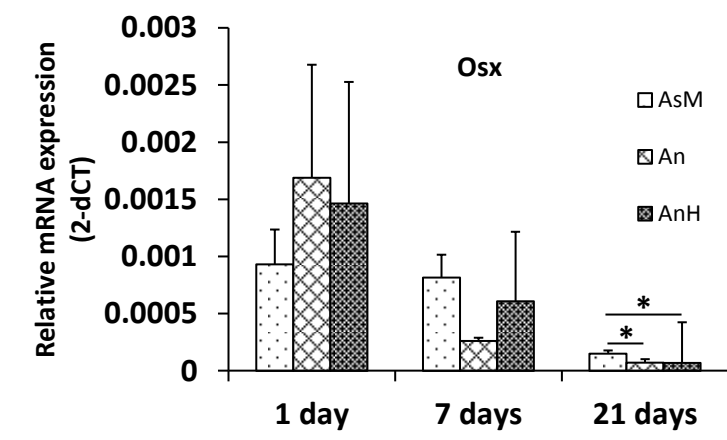

d) b)

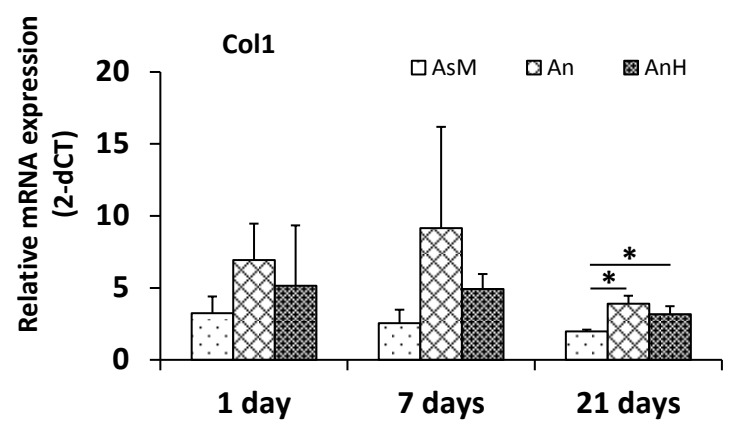

c)

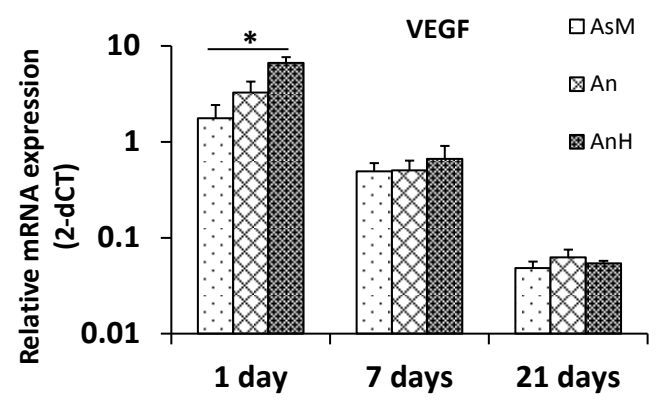

e) 